\title{
Altzairu-zuntzez indarturiko hormigoia: Eraikuntza lanak erraztuko dituen etorkizun oparoko materiala
}

\author{
Aimar Orbe \\ Eraikuntza Ingeniaritza, Ingeniaritza Mekanikoa Saila, \\ Bilboko Goi Ingeniaritza Eskola, Euskal Herriko Unibertsitatea \\ (UPV/EHU) \\ aimar.orbe@ehu.eus
}

DOI: 10.1387/ekaia.14494

Jasoa: 2015-05-13

Onartua: 2015-09-30

Laburpena: Altzairu-zuntzez indarturiko hormigoia, AZIH (ingelesez SFRC), arrunki ezagutzen dugun hormigoi armatuaren anaia txiki eta ezezaguntzat har genezake. Hala ere, bere ibilbidea anaia zaharrenaren eskutik egin du teknologia hauen garapenean zehar, eta orain etorkizun oparoa aurreikusten zaio. Aldi berean, azken bolada honetan garatzen dabiltzan hainbat azterketa teknika ez-suntsikorrek, kalitate kontrol erraz eta zehatza egitea ahalbidetzen dute. Hori baita AZIHak duen desabantailetako bat, hau da, behin hormigoia gogortuta, ez da hain erraza zuntzek hormigoi matrizearen baitan hartzen duten orientazioa ikusten. Hala ere, materialak merkatuan harrera ona izan dezan, ezinbestekoa da laborategiko maila gainditu eta eskala errealeko egitura-osagaien ikerketa bultzatzea.

Hitz gakoak: Hormigoia, Zuntzak, Altzairua, Saiakuntza ez-suntsikorrak.

Abstract: Steel fibre reinforced concrete, SFRC, could be considered the little and unknown brother of the commonly known reinforced concrete. However, his trajectory has gone hand in hand with his elder brother during the development of these technologies and a promising future is foreseen. At the same time, the recent development of non-destructive testing techniques allow an easy and accurate quality control. This is crucial, since the main disadvantage of the SFRC is that it is not evident which the orientation of the fibres within the concrete matrix is once the concrete is hardened. Nevertheless, it is essential to overcome the laboratory level and to promote the study of real structural elements, so that materials are well received in the market.

Keywords: Concrete, Fibres, Steel, Non-destructive testing. 


\section{SARRERA}

Altzairu-zuntzez indarturiko hormigoiak (AZIH), bere izenak dioen bezala, hormigoi matrize hauskorra josten duten milaka zuntz labur eta ausaz kokatuez osatuta dago (1 Irudia). Ausazko kokapen hori, hala ere, mugatua izan daiteke perimetroko enkofratuaren eraginez edo hormigoiaren jariakortasunak sortzen duen fluxu-mugimenduaren arabera, eta zuntzak plano edo norabide jakin baten arabera orientatzera behartuta daude. Gaur egun, zoladuretan eta tuneletan erdi bana erabiltzen da batik bat AZIHa. Lehenengoen artean, industria-eraikin eta portu zein aireportuetako zoladura elementuak nabarmen daitezke eta bigarrenean, dobela aurrefabrikatuen zein euste lanetarako proiektatzen den hormigoiaren baitan aurki daiteke. Beste erabilerak, altzairu-zuntzaren ekoizpenaren \%1a besterik ez dira.

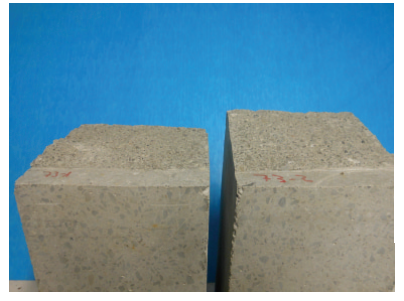

(a) Hormigoi hutsa

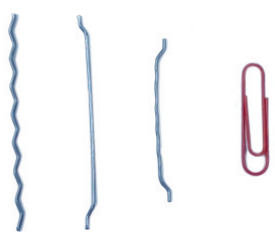

(b) Zuntz motak

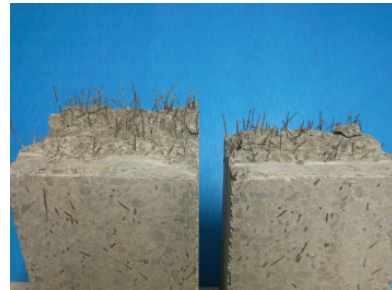

(c) AZIH

1. irudia. Zuntzez indarturiko hormigoiaren eta indartu gabeko hormigoiaren aldea.

Gaur egun, gutxi dira material honen saiakuntza eta diseinu-oinarriak zehazten dituzten kode edo arauak. Hala ere, ikerketa esperimentalen ondorioek adostasun txikia eragin dute, herrialde bakoitzean parametro eta prozedura ezberdinei jarraiki ezartzen baita materialaren portaera mekanikoa [1]. Hala ere, araudian ahaztua gertatu da, baina aspaldikoa da eraikuntza materialak zuntz ezberdinekin indartzeko joera. Hala egiten da lastoarekin edo belar onduarekin nahasitako buztinaren kasuan, adobe adreiluak sortzeko. Ezaguna den hiririk zaharrenean adibidez, Anatoliako Çatal Höyükek, material hau erabili zuten etxeen hormak eraikitzeko K.A. VIII milurtekoan.

Gaur egun, material teknologikoagoak erabiltzen dira, eraikuntzek bermatu beharreko ziurtasun-baldintzak betetzen direla egiaztatzeko. Horien artean, oso aipagarriak dira beira, karbono eduki gutxiko altzairukoak eta sintetikoak. Azken hauetan polipropilenoz osatuak dira nagusi. Badira, hala ere, egur zelulosa edo koko zuntza bezalako material batzuk, zuntz laburren itxura hartuta hormigoia era berri batez indartzeko erabiltzen direnak. 
A. Bernardek 1874an erregistratu zuen hondakinetatik berrerabilitako altzairu-ezpalak hormigoia indartzeko lehen patentea, Jean-Louis Lambot (1856) eta Joseph Monieren (1867) patenteak baino urte gutxi beranduago bakarrik. Azken bi hauek, hormigoi armatuaren aitzindariak dira, baina ez dakigu lehenengo asmatzailea nor izan zen. Urteak joan ahala, ugariak izan ziren altzairu-zuntzez indarturiko hormigoiaren patenteak, baina erabilera nahiko murritza izan zen, paraleloan garatu zen barra bidezko hormigoi armatuagatik. Erabilerak gora egin zuen James Romualdiren (1962) saiakuntzek emandako bultzadari esker. Etenik gabeak izan dira propietate mekanikoak ezagutzeko ikerketak eta materialarentzako egokiak izan daitezkeen balizko erabileren bilaketa [2].

\section{MATERIALAREN OINARRIAK}

Hormigoi-matrizea, material hauskorra da, eta bat-bateko apurketa eragiten da behin bere trakzio tentsioa gainditzen dela. Trakzio-erresistentzia hori, konpresio-erresistentziarekiko alderatuz gero oso baxua da eta ez da sarri kontutan hartzen. Hori dela eta, ezinbestekoa da hura indartzea trakzioei eutsiko dien materialen batekin. Altzairu barra korrugatuak erabiltzea da ohikoena eta hedatuago dagoen hormigoi armatua osatzen da. Altzairuak, hormigoiaren antzekoa den dilatazio koefizientea du eta itsasgarritasun egokia agertzen du, bai barrek gainazalean dituzten izur itxurako formei esker, bai zementuaren hidratazio prozesuan sortzen den geruzari esker. Material konposatu honen pareko portaera azaltzen du AZIHak, baina kasu honetan diametro eta neurri askoz txikiagoko zuntzen bitartez eusten dira trakzio indarrok.

Nahiz eta karbono eduki gutxiko altzairua erabili zuntzen fabrikazioan, nekez heltzen da zuntzen haustura eragingo duten balioetara. Aldiz, zuntzen eta hormigoi-matrizearen arteko irristatzea sarri izaten da karga eusteko ahalmena mugatzen duen fenomenoa. Hastapenetan ezpal, eraztun edo beste forma ugari erabili ziren, baina azkenean zuntz zuzenen erabilera nagusitu zen. Hala ere, azken hamarkadetan egin diren ikerketen harira, forma okertu edo ez-zuzenak gailendu dira, hormigoi matrizearen baitan ainguraketa hobea eskaintzen baitute. Horien artean, muturrak gako eran okertuak dituzten zuntzak eta zuntz ondulatuak dira nagusi (1b Irudia). Badira beste forma batzuk, aurreko biak uztartzen dituztenak, mutur zapalak dituztenak edo ainguraketa ezin hobea eskaintzen duten mutur konikoak. Hala ere, erabilera oso txikia da fabrikazio-kostuen gorakada dela eta.

Hormigoi-matrizea urratzen hasten denean, altzairu-zuntzak lanean hasi eta kargari eusten diote hausturaren plano batetik bestera, alderdi biak josirik mantenduz. Kargak handitzen joan ahala, zuntzak irristatzen hasten dira matrizearen baitan, materialen arteko itsasgarritasun eta ainguraketa mekanikoko fenomenoak gainditzen diren heinean. Zuntzak plastikoki deforma- 
tuz doaz, matrizearen barnean sortu duten bidetik zehar ateratzen doazen bitartean. Zuntzak hautsi edo guztiz erauzten diren heinean, erresistentzia-mekanismoa ahulduz doa. Zuntzak bolumen txikian $(\% 0,45$ - eta $\% 0,75$ tartean) gehitzea nahikoa da hormigoiaren harikortasuna eta zailtasuna, deformazio plastikoaren bidez hautsi gabe energia xurgatzeko ahalmena, handitzeko. Erabilera askotan, makurtutako lauzetan adibidez, nahikoa da hobekuntza hori hormigoiaren trakzio-erresistentzia kontutan ez hartu eta konprimitutako alderdiarekin bat, egituraren beharrezko segurtasun maila bermatuko duen oreka egoera lortzeko. Hala ere, badira hainbat ikerketa ildo erresistentzia handiko AZIHak lortzeko bidean dihardutenak altzairu-zuntz bolumen handiak gehituz ( $\geq \% 2)$.

\section{KALITATE-KONTROLA}

Argi dago ezinbestekoa dela materialaren ezaugarri eta propietate mekanikoak ezagutzea, bere bizitza zikloan zehar izango duen portaera aurrez bermatzeko. Hala ere, zuntzen ausazko kokapen eta orientazioa ez da agerikoa eta begiratu batean ezinezkoa da hormigoi gogortuaren barnean zelan kokatuak dauden zehaztea.

Azken bolada honetan, hainbat dira kalitate kontrola errazteko nahian buru-belarri diharduten ikertzaileak. Argi dago osagaia edo lagina txikitu eta zuntz guztiak erauzi eta pisatzean datzala hormigoi barruko zuntz kopurua zehatz mehatz zehazteko erarik zuzen eta fidagarriena, baina baita suntsikorrena ere. Horrek, kalitate-kontrol neketsu eta garestia egitea dakar. Horretaz gain, ezin da eskuratu zuntzek hartu duten orientazioari buruzko informazio baliagarririk. Helburu hori ikusmiran, metodo estereologiko ugari aplikatu dira, elementu edo laginak moztu ondoren, ebakidura lau horietan agertzen diren zuntz kopurua zenbatuz edo irudi bidezko analisiak eginez.

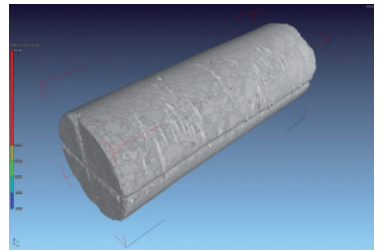

(a) Lagina

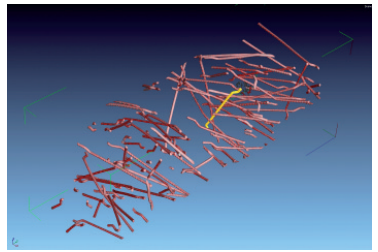

(b) Zuntzak

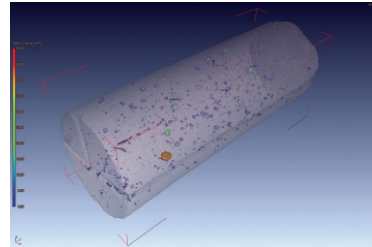

(c) Poroak

2. irudia. Ordenagailu bidezko tomografia axiala (OTA).

Traba horiek gainditu nahian, saiakuntza ez-suntsikorren garapena sustatu da. Ordenagailu bidezko tomografia axialak, OTA (ingelesez CT) (2 Irudia), hormigoi-matrizearen barrena zehaztasun osoz agertzen du, zun- 
tzak, poroak edo beste edozein gorputz erakutsiz. Hala ere, teknika honen kostu altuak eta lagina ez den egitura-osagai osoan erabiltzearen ezintasunak, haren erabilera sistematikoa baztertzera behartzen du. Beste ikerketa askotan, material konposatuaren propietate elektriko eta magnetikoez baliatzen dira zuntzen kopuru eta orientazioa zehazteko. Horien artean oso aipagarriak dira korronte alternoko inpedantzia-espektroskopia (AC-IS ingelesez) [3], erresistibitate elektrikoa [4], transmisio lerro ardazkidea zirkuitu irekian [5], antena uhin-gidariak [6] eta metodo magnetikoak [7]. Hauetatik guztietatik, metodo magnetikoek dirudite etorkizun handienekoak, tresneria konplexurik erabiltzen ez duen teknika sinplea baita.

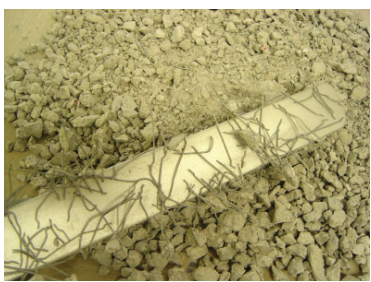

(a) Zuntz-erauzketa

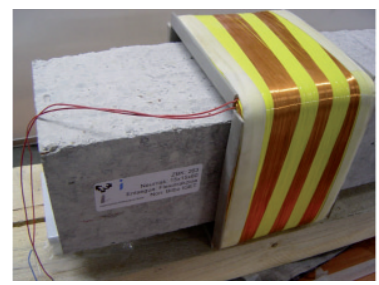

(b) Metodo magnetikoa

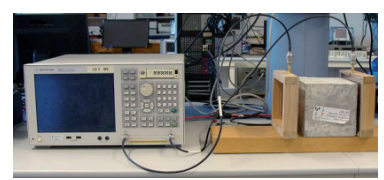

(c) Antena uhin-gidariak

3. irudia. Zuntz erauzketa eta teknika ez-suntsikorren arteko aldea.

Bestalde, frogatuta dago metodo magnetikoek informazio zehatza eman dezaketela zuntzen kopuru eta orientazioari buruz [8]. Helburu hori ikusmiran, kobrezko kablez egindako harilak sortzen duen eremu magnetiko baten barruan sartzen da AZIH lagina. Hormigoia eremu horren baitan «gardena» den arren, bertan barneratzen diren elementu ferromagnetikoek, adibidez altzairu-zuntzak, harilaren autoinduktantziaren balioa aldatzen dute, induktantzia horren balioa aldaraziz. Aldaketa horren balioa, eremu magnetikoarekin lerrokatuta dauden zuntzen kopuruarekiko proportzionala da, hau da, zenbat eta aldaketa handiagoa izan, hainbat eta zuntz gehiago. Azpimarratzekoa da, induktantzia aldaketa eragin dezaten, zuntzek eremu magnetikoarekin lerrokaturik egon behar dutela; zuntz elkarzuten eragina ez da kontutan hartzeko bezainbestekoa. Beraz, neurketok laginen hiru ardatz nagusiekiko eginez gero, zuntzek espazioan duten banaketa ezagut daiteke. Aldi berean, hiru neurketa horien bataz besteko balioak ere, laginak duen zuntz kopuru osoaren informazioa eskaintzen du. Era honetan, laginaren indartzearen azterketa egiten da lagina kaltetu gabe. Horrela, posible egiten da konpresio-erresistentziarena bezalako saiakuntza gehiago egitea. Teknika ez-suntsikor hauek guztiek, hondakin gutxiago sortzen dituzte, eta alderdi horretatik, jasangarritasunaren alde ere egiten dute.

Hormigoi eta zuntzen ezaugarri mekanikoak aztertzerakoan, nahikoa da gaur egun erabiltzen den kontrol estatistikoaz baliatzea. Proiektuan erabili 
beharreko materiala multzotan banatzen da eta multzo horietatik berariaz prestatutako laginak izango dira laborategiko saiakuntzen bidez kontrolatuko direnak. Hala ere, zuntz bidezko indartzearen berezitasuna dela eta, gaur egun beharrezkoa suertatzen da eraiki den egituran bertan saiakuntzak egitea. Lagin eta egitura-osagaien baitan zuntzen orientazioa oso bestelakoa izan daiteke eta horrek, segurtasun gabezia dakar. Hori dela eta, laginetan egindako saiakuntzetan erdietsitako balioak, egiturarekin egindako entsegu ez-suntsikorrekin alderatu behar dira. Teknika berri hauek gauzatzea arin eta sinplea denez, komenigarria litzateke neurketa-ekipoak garatu, gailu mugikor bati atxiki eta etengabeko neurketen erregistroa biltzea egituraren indartze-mapa osatzeko.

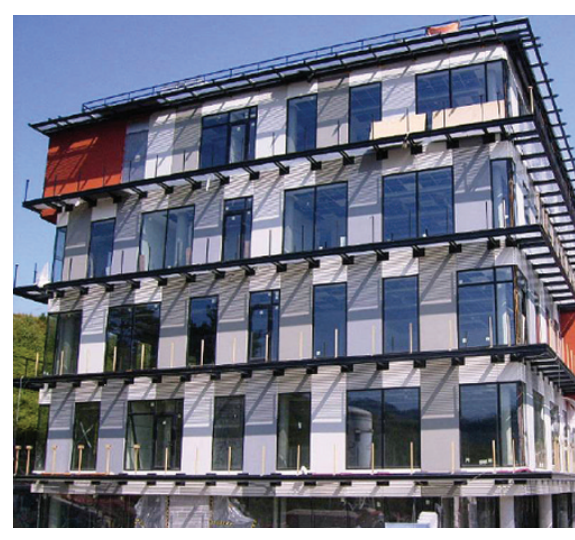

(a) Eraikinaren ikuspegia

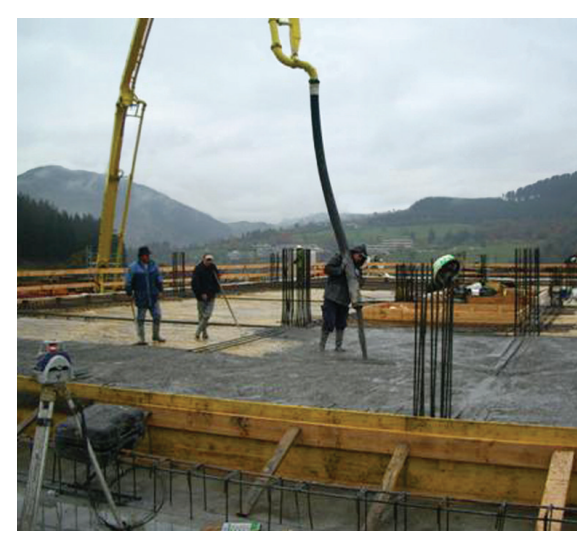

(b) Egikaritzea

4. irudia. LKS Ingeniaritzaren egoitza nagusia (Aitor Maturana).

\section{HURBILEKO KASU PRAKTIKOAK}

Asko oraindik ohartu gabe badaude ere, gure inguru hurbilean hainbat dira AZIH erabiltzen duten egitura eta elementuak. Hona hemen aipagarrienak: Bilbao Exhibition Centreko pabilioien lauzak, Bermeoko portua, Metro Bilbaoren tunel tarte baten sostengua eta LKS ingeniaritza-enpresaren egoitza nagusia (4 Irudia). Lehenengo biak zoladuren taldean sailka daitezke, baina nahiz eta zama handiak jasan behar izan, azalera osoan zehar lurrean bermatzen diren elementuak dira eta beraz, ez dute makurdura esfortzu larregirik pairatzen. Tunelaren sostenguari dagokionez, harkaitz zati txikiak askatu eta trenbidera jauztea ekiditen duen elementua da. Elementuaren geometria zilindrikoa izanik, kanpoaldetik eutsi beharreko bultzadek konpresio esfortzuak eragiten dituzte batik bat, eta horrela nolabait arintzen da zuntzen trakzioak eusteko betebeharra. 
Adibide horien artean azkena da deigarriena. LKSren eraikineko solairu ezberdinak osatzen dituzten forjatuak, AZIH bitartez diseinatu eta eraikitako lauza trinkoak dira. Forjatuek 660 metro karratu inguruko azalera dute solairu bakoitzeko, eta $300 \mathrm{~mm}$-ko lodierako lauzak zuzenean zutabeen gainean bermatzen dira, inolako haberen beharrik gabe. Zutabeen artean forjatuek osatzen duten erretikula zati handienek, $8 \times 7,8$ metroko azalera ia karratua aurkezten dute. Kasu honetan, norabide bitan makurtuko den egitura-osagaiak hobeto balia ditzake zuntzen abantailak, ohiko barren muntaia lanak aurreztu eta eraikitze denborak murrizteko. 4 Irudian argi ikusten da, zutabeen arteko lerrokadurek dituzten barrak salbu, lauza osoan ez dela zuntzez indarturiko hormigoia besterik isuri. Euskal Herriaz gain, inguruko herrialdeetan AZIHarekin eraikitzen den lehena izateak entsutetsu bihurtu du eraikin hau, maila profesional eta akademikoan.

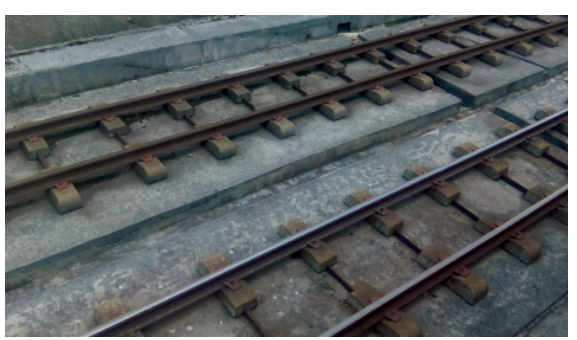

(a) Bilboko metroa

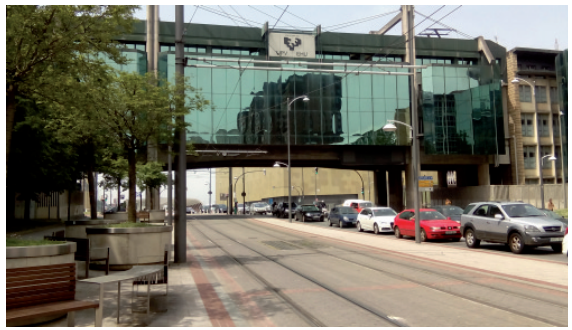

(b) Bilboko tranbia

5. irudia. Trenbide lauzen adibideak.

\section{ETORKIZUNEKO IKERKETA ILDOAK}

Etorkizunari begira, hainbat dira material honetan oinarri daitezkeen erabilerak. Argi dago azalera handiko elementu lauak direla egokiena, zuntzen bidez lor daitekeen esfortzu-birbanaketaz erarik eraginkorrenean baliatzeko. Egilea parte duen ikerketa taldea hortan dihardu eta begin onez ikusten da, trenbideetako balastoak eragiten dituen mantentze kostu handiak murrizteko erabiltzen hasi diren trenbide lauzetan (5 Irudia), zuntzak erabiltzea indartze gisa. Era honetan, lauzen abantailak mantentzeaz gain, zuntzek dakartzaten lanen denbora, kostu eta eragozpen murrizketak ere gehituko lirateke.

Arestian aipatu diren zuntzen zenbateko eta orientazioa zehazteko erabil daitezkeen saiakuntza ez-suntsikorrez gain, ordenagailu bidezko jariakinen dinamika (ingelesez CFD) teknikak etorkizun handikoak suerta daitezke hormigoi jariakorren kasuan. Era honetan, isurketa prozesuan eta enkofratua bete arteko mugimenduan hormigoiaren deformazio-tentsoreak aztertuz, zuntzek har dezaketen orientazioari buruzko informazio baliagarria esku- 
ratuko da egitura-osagaiaren edozein gunetan [10]. Aldi berean, material hauen jasangarritasunaren ikuspuntua indartzeko, pitzatuak berez osatuko dituen hormigoiak garatzeko bidean gaude. Hormigoiaren osagarri guztiei gehigarri kristaltzailea gehituz, zementuaren hidratazio prozesuak latente iraun dezake. Hori dela eta, pitzadurarik gertatuz gero ur ekarpen sinplea nahikoa izan daiteke haustura horiek ixteko mekanismoa abiatzeko eta horrela, dagokion erresistentzia maila segurtasun osoz berreskura daiteke [11].

\section{ESKERTZAK}

Egileak, eskertu egin nahi ditu Ingeniaritza Mekanikoa eta Komunikazio Ingeniaritza Saileko ikertzaileen lankidetza, IT781-13 ikerketa taldearen laguntza eta ArcelorMittal-Wire Solutions and Financiera y Minera (Italcementi Group) enpresen parte hartzea.

\section{BIBLIOGRAFIA}

[1] ORBE A. 2013. «Erresistentzia moderatuko ohiko aplikazioetan altzairu zuntzez indarturiko hormigoi autotrinkotzailearen erabileraren optimizazioa». Doktore tesia-Universidad del País Vasco / Euskal Herriko Unibertsitatea (UPV/EHU), 327 orri.

[2] ORBE A., CUADRADO J., LOSADA R. eta ROJÍ E. 2012. «Framework for the design and analysis of steel fiber reinforced self-compacting concrete structures». Construction and Building Materials, 35, 676-686.

[3] OZYURT N., MASON T.O. eta SHAH S.P. 2006. «Non-destructive monitoring of fiber orientation using AC-IS: An industrial-scale application». $\mathrm{Ce}$ ment and Concrete Research, 36, 1653-1660.

[4] LATASTE J., BEHLOUL M. eta BREYSSE D. 2008. «Characterisation of fibres distribution in a steel fibre reinforced concrete with electrical resistivity measurements». NDT; E International, 41, 638-647.

[5] VAN DAMME S., FRANCHOIS A., DE ZUTTER D. eta TAERWE L. 2004. «Non-destructive determination of the steel fiber content in concrete slabs with an openended coaxial probe». Geoscience and Remote Sensing, IEEE Transactions on, 42, 2511-2521.

[6] ROQUETA G., JOFRE L., ROMEU J. eta BLANCH S. 2010. «Broadband Propagative Microwave Imaging of Steel Fiber Reinforced Concrete Wall Structures». Instrumentation and Measurement, IEEE Transactions on, 59, 3102-3110.

[7] TORRENTS J., BLANCO A., PUJADAS P., AGUADO A., JUANGARCÍA P. eta SÁNCHEZ-MORAGUES M. 2012. «Inductive method for assessing the amount and orientation of steel fibers in concrete». Materials and Structures, 45, 1577-1592. 
[8] ORBE A., ROJÍ E., LOSADA R. eta CUADRADO J. 2014. «Calibration patterns for predicting residual strengths of steel fibre reinforced concrete (SFRC)». Composites Part B: Engineering, 58, 408-417.

[9] MATURANA A., CANALES J., ORBE A. eta CUADRADO J. 2014. «Plastic Analysis and Testing of multidirectional SFRC flag slabs». Informes de la Construcción, 66, e031.

[10] ORBE A., LOSADA R., ROJÍ E., CUADRADO J., eta MATURANA A. 2014. «The prediction of bending strengths in SFRSCC using computational fluid dynamics (CFD)». Construction and Building Materials, 66, 587-596.

[11] FERRARA L., KRELANI V. eta CARSANA M. 2014. "A fracture testing based approach to assess crack healing of concrete with and without crystalline admixtures». Construction and Building Materials, 68, 535-551. 